Journal of Sustainable Development of Transport and Logistics

journal home page: https://jsdtl.sciview.net

Ganepola, D. D., Jayarathna, N. D., \& Madhushani, G. (2018). An intelligent cost optimized central warehouse and redistribution root plan with truck allocation system in Colombo region for Lion Brewery Ceylon PLC. Journal of Sustainable Development of Transport and Logistics, 3(2), 66-73. doi:10.14254/jsdtl.2018.3-2.4.

\title{
An intelligent cost optimized central warehouse and redistribution root plan with truck allocation system in Colombo region for Lion Brewery Ceylon PLC
}

\author{
Dilan Dhanushka Ganepola (D), Nuwan Dhammika Jayarathna (D), \\ Ganga Madhushani \\ Colombo International Nautical Engineering College, \\ Hayleys Advantis, 1st Floor, Thurburn Wing, 400, Deans Road, Colombo 10 01000, Sri Lanka \\ Faculty of Management and Social Sciences, Department of Logistics and Transport
}

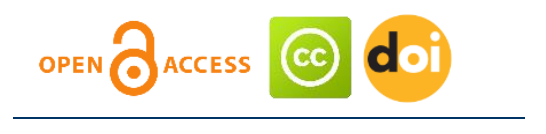

Article history:

Received: August 16, 2018

1st Revision: September 9, 2018

Accepted: October 22, 2018

\section{DOI:}

10.14254/jsdtl.2018.3-2.4

\begin{abstract}
This research is a case study based on Lion Brewery Ceylon PLC, Biyagama, which is a famous beer company and the market leader in Sri Lanka. Researcher identifies that, currently Company outbound logistics is consisted with a decentralized distribution and a redistribution process for bottles and cans in Colombo region, and an extra cost is being spent for that unnecessarily. The main objective of this research is to build a cost minimized model for distributing Bottles and Cans for the region. For that, all demand regions in Colombo region was divided in to main 6 sub clusters. Then a centralized Warehouse and an optimal path which joins each sub cluster has been determined. The gravity model (By using excel solver) was used to find a centralized warehouse that can easily be connected with each sub cluster. The optimal path was determined through Hamiltanian cycle by using the lingo software. Finally, the milk run was completed with determining a cost optimized truck allocation system through linear programming model. At the end result proved that, the proposed model saves the monthly cost of bottles distribution by $17.2 \%$ and monthly cost of cans distribution by $11.6 \%$.
\end{abstract}

Keywords: Centralize, decentralize, transport planning. 


\section{Introduction}

Lion Brewery Ceylon PLC is one of the leading beer companies in Sri Lanka. Lion beer brands are very popular among people. Core functions of the Company is manufacturing and distributing beer in domestically and internationally. To be a market leader in the industry, company needs customer attraction. As well as should reduce unnecessary costs invoved in the key areas of the business.The process of supply chain and Logistics plays a crucial role in the distribution process of beer . Company has allocated a very high percentage from its budget, for this process. Among many areas where the company is engaged in distribution.

The highest demand can be seen in Colombo region. There are three agents, who are operating in Colombo region and 16 redistribution Lorries are being involved in the process. Those Distributors locations are established in Boralasgamuwa, Colombo 6 and Colombo 13. In the current decentralized redistribution process of the company, researcher sees an extra cost. Therefore the purpose is to suggest a centralized distrbution process to reduce the costs enaged with logistics.

Figure 1 : Lion Brewery Logistics Process

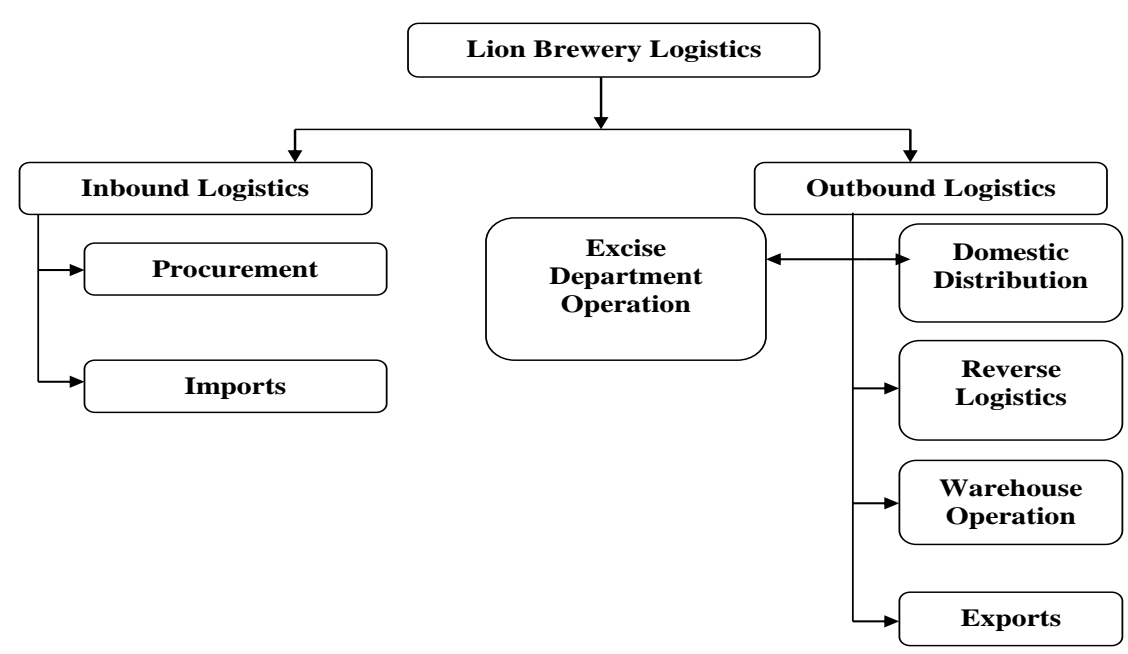

Source: Constructed by the author

\section{Literature review}

Bidaud and Safir (2007-2008) conducted a research of Pre-study for a central Warehouse. Researchers have given a solution for European $3^{\text {rd }}$ party logistics distribution process through a centralized Warehouse. By taking the project location as the main objective, to find the optimal location, the researchers have considered Gravity Model.

\section{Metodology}

\section{Gravity model}

In location analysis, Gravity model is the most common, simply and widely used. The exact location is given by the Newtonian Gravity formula. It is including location of the customer and weight associated demand. The Solution has given new location's latitude and longitude and it is economical and optimized location of new facility warehouse.

Drezner, Scott and Song (2009) conducted a research of the central warehouse location problem revisited. The Purpose of the research was to find a central warehouse location with introducing optimum solutions. They have indicated that, Most important and optimal solution is to minimize the transportation cost while finding best location of problems in the central warehouses.

When finding locations of central warehouses, normally inventory cost is ignored. But warehouse location is considered by warehouse inventory problems. As well as location is considered very little when solving inventory problems. Optimum level of inventory cost is very conflicted in general. Numerical methods are given solution to 
inventory methods with optimized algorithms. They have taken some reasonable assumptions to overcome disturbances of this research. For the analyzing and solving problems, they proposed four methods. First one is the back order cost and they have taken second one as a most common method. It can be calculated back order cost by using service level of system and normally service level has been given to calculation. They have stated that it is very difficult process of estimating good will cost. As the third method, it can be defined as keeping high service level is the most influential rather than reducing the cost. It means objective of the third method is to increase the service level. Weber location problem is the last method of analysis and it is ignored inventory cost. They have mentioned that numerical result shows ideal location of new facility rather than existing location. Researchers have verified ideal location for a new facility by reducing inventory cost and transportation cost.

Sahoo and Pal (2012) conducted a research of truck allocation model using linear programming and queueing theory. Queueing theory is the special design of telephone system and it is being used for control traffic, in hospital management and it was designed computer system of time shared. When solving optimization problems in transport problems and operational research, linear programming is being taken. In linear programming problems, which is included a linear objective function, constrains and non negative constrains but in non linear programming problems, which is including non linear objective function and constrains. Simplex method is given either basic feasible result or solution in an effective manner.

The researcher has introduced new truck allocation model with reducing wastage of time through increasing operational improvements and optimized route planning. Truck allocation model has been built using linear programming and Queueing theory assuming that single truck size.

Research of economic evaluation of a warehouse investment in central Europe has conducted by Machackova (2009). The Research was based on Nokian Heavy Tyres ltd and it was an ongoing project in 2009. The researcher has comprised eminent analysis of warehouse physical location in central Europe. The goal was to build a warehouse for Nokian Heavy Tyres in central Europe when comparing private warehouse and contract warehouse. The researcher has taken three alternatives under warehouse planning

Michael Haythorpe has carried out a research of Markov chain based algorithms for Hamiltonian cycle problem. Research has embedded Hamiltonian cycle problem to Markov decision process. Hamiltonian cycle is famous for solving traveling salesmen problem. Optimization problems are applied by Hamiltonian cycle problem and Markov decision process. Through that he has developed new theoretical results with that optimization models. Methods have been conducted a path like branches of tree to find a Hamiltonian cycle. Researcher has considered three graphs. First one is the one or more Hamiltonian cycles which contained by Hamiltonian graphs and Second one is the non Hamiltonian cycles which conducted by Bridge graphs but it could be found out in polynomial time. Third one can be defined as neither all graphs those are neither Hamiltonian nor one connected which conducted by non Hamiltonian graphs. The researcher has tested travelling salesmen problems using these methods and proved optimized paths.

Andrew Chalaturnyk (2008) has conducted a research of a fast algorithm for finding Hamiltonian cycles. This thesis was done by researcher as an algorithmic study and it was applied with Hamiltonian cycle problem. He has used two methods for the research and first one is the Graph theory concept. In this concept he used basic terminology and graphical representation to prove the concept. Set of vertices and edges are composed for the graphs. Paths and cycles were applied for the concept and after checked connectivity for each path. Second one is the Multi path method and it was used to find Hamiltonian cycle.

\section{Research results}

Lion Brewery Ceylon PLC is the beer market leader in Sri Lanka since 1881 for Lion Lager, Strong, stout and word famous Carlsberg beer brewer in Sri Lanka. According to the monthly sales data which are collected from SAP ERP system and agent operation data base it has shown small variation but not too much in Colombo region. There are 18 distributors operate in Sri Lanka and among that, three distributors operate in Colombo region. Following table is giving average monthly sales in Colombo region distributors. 


\begin{tabular}{lccc} 
Table 1: Average sales of Colombo region & Average Daily Demand \\
Distributor & $\begin{array}{c}\text { Average Monthly Demand } \\
\text { (Dozens) }\end{array}$ & $\begin{array}{c}\text { Daily Total Average } \\
\text { Demand (Dozens) }\end{array}$ \\
\hline Colombo 06 & 46495 & 1788 & 7754 \\
Colombo 13 & 66858 & 2571 & \\
Boralasgamuwa & 88251 & 3394 & \\
\hline
\end{tabular}

Source: Constructed by the author based on SAP data

Table 1 is explaining average monthly sales of Colombo 6, Colombo 13 and Boralasgamuwa distributors. Daily sales of Colombo region is 7754 dozens.

\section{Gravity Model Formula}

Gravity Model is used to find optimal location and it is proposed by Geramy Bidaud (2007/08).

$$
X=\frac{\sum_{i}^{n} W i \times x C i}{\sum_{i}^{n} W i} Y=\frac{\sum_{i}^{n} W i \times y C i}{\sum_{i}^{n} W i}
$$

$\mathrm{n}$ is the no of area ( cluster $1,2,3 \ldots \ldots . ., 35$ )

$\left(y C_{i}, x C_{i}\right)$ is the given location coordinates with the $\mathrm{i}$-th area (latitude \& longitude)

$W_{i}$ is the weight associated with the $\mathrm{i}^{\text {th }}$ area

$(X, Y)$ is the unknown location co-ordinates of the new warehouse facility.

To Find a exact location of central warehouse, Gravity model equation has been used. Above gravity model is given exact location of the central warehouse and it is situated in latitude 6.887700861 and longitude 79.90165817.

Colombo region is divided into 35 clusters. And those clusters divided into five main clusters according to the geographical situation. Following table is given five main clusters under 35 clusters in Colombo region with daily demand.

\section{Table 2: Colombo Region Daily Demand in Clusters wise}

\begin{tabular}{|c|c|c|c|}
\hline \multicolumn{2}{|c|}{ Cluster 1} & \multicolumn{2}{|c|}{ Cluster 4} \\
\hline Area & Average Demand & Area & Average Demand \\
\hline Colombo 1 & 103 & Kottawa & 61 \\
\hline Colombo 9 & 368 & Pannipitiya & 235 \\
\hline Colombo 11 & 633 & Maharagama & 245 \\
\hline Colombo 12 & 212 & Nugegoda & 244 \\
\hline Colombo 13 & 357 & Homagama & 169 \\
\hline Colombo 14 & 211 & Padukka & 76 \\
\hline Colombo 15 & 220 & Hanwella & 210 \\
\hline \multicolumn{2}{|c|}{ Cluster 2} & \multicolumn{2}{|c|}{ Cluster 5} \\
\hline Area & Average Demand & Area & Average Demand \\
\hline Colombo 2 & 289 & Boralasgamuwa & 124 \\
\hline Colombo 3 & 249 & Dehiwala & 361 \\
\hline Colombo 4 & 71 & Mt. Lavinia & 122 \\
\hline Colombo 5 & 301 & Rathmalana & 110 \\
\hline Colombo 7 & 58 & Moratuwa & 463 \\
\hline Colombo 8 & 160 & Piliyandala & 339 \\
\hline Colombo 10 & 170 & Colombo 6 & 277 \\
\hline \multicolumn{2}{|c|}{ Cluster 3} & & \\
\hline Area & Average Demand & & \\
\hline Battaranulla & 225 & & \\
\hline Thalawathugoda & 139 & & \\
\hline Malabe & 167 & & \\
\hline Kaduwela & 103 & & \\
\hline Athurugiriya & 185 & & \\
\hline Gothatuwa & 291 & & \\
\hline Rajagiriya & 208 & & \\
\hline
\end{tabular}

Source: Constructed by the author based on SAP data 


\section{Route Analysis - Hamiltonian Cycle}

As a second step of the research is to find a route plan with optimal path is done by using lingo software. Lingo is software which is made for easy to solve liner and non linear optimization problems. Through that, Hamiltonian cycle sample model is adjusted to this research and it is solved by using Lingo software. Hamiltonian cycle is given optimal path to each main cluster. Adjusted Hamiltonian cycle sample problem is given bellow. After solving model, when value is showed 1 , it is taken as a path.

MODEL:

! Traveling Salesman Problem for the cities of

New Facility, Colombo 01, Colombo 09, Colombo 11, Colombo 12, Colombo 13, Colombo 14, Colombo 15;

SETS: CITY / 1.. 8/: U; ! U( I) = sequence no. of city;

LINK( CITY, CITY):

DIST, ! The distance matrix;

$\mathrm{X} ; \mathrm{I} \mathrm{X}(\mathrm{I}, \mathrm{J})=1$ if we use link I, J;

ENDSETS

In order to the solution of Cluster 1 Optimal paths with distance are given bellow.

Figure 2 : Cluster 1 - Optimal Path and Distance

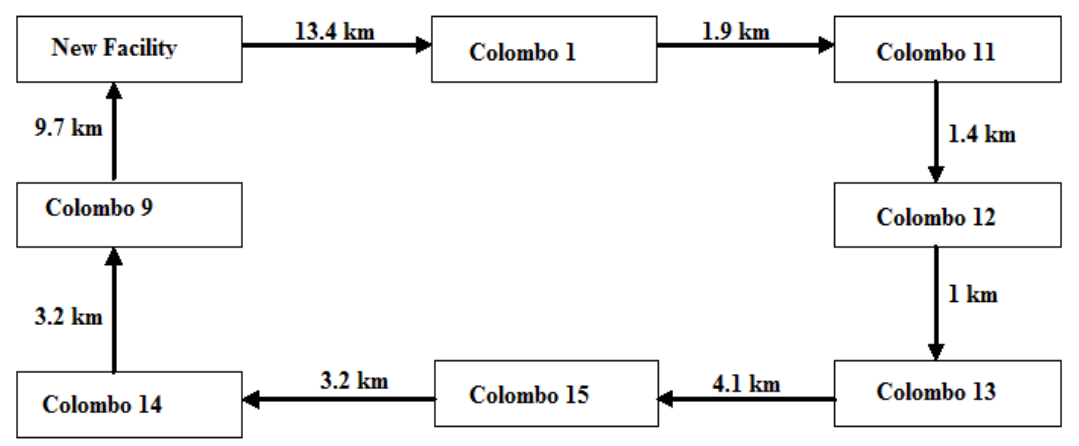

Source: Constructed by the author

After finding optimal path of each Clusters, total milk run as follows.

\section{Table 3: Daily Milk Run Kilometers}

\begin{tabular}{cc}
\hline Cluster & Daily Milk Run km \\
\hline 1 & 38 \\
2 & 27 \\
3 & 51 \\
4 & 66 \\
5 & 38 \\
Total & 220 \\
\hline
\end{tabular}

Source: Constructed by the author 
Figure 3: Truck allocation Structure

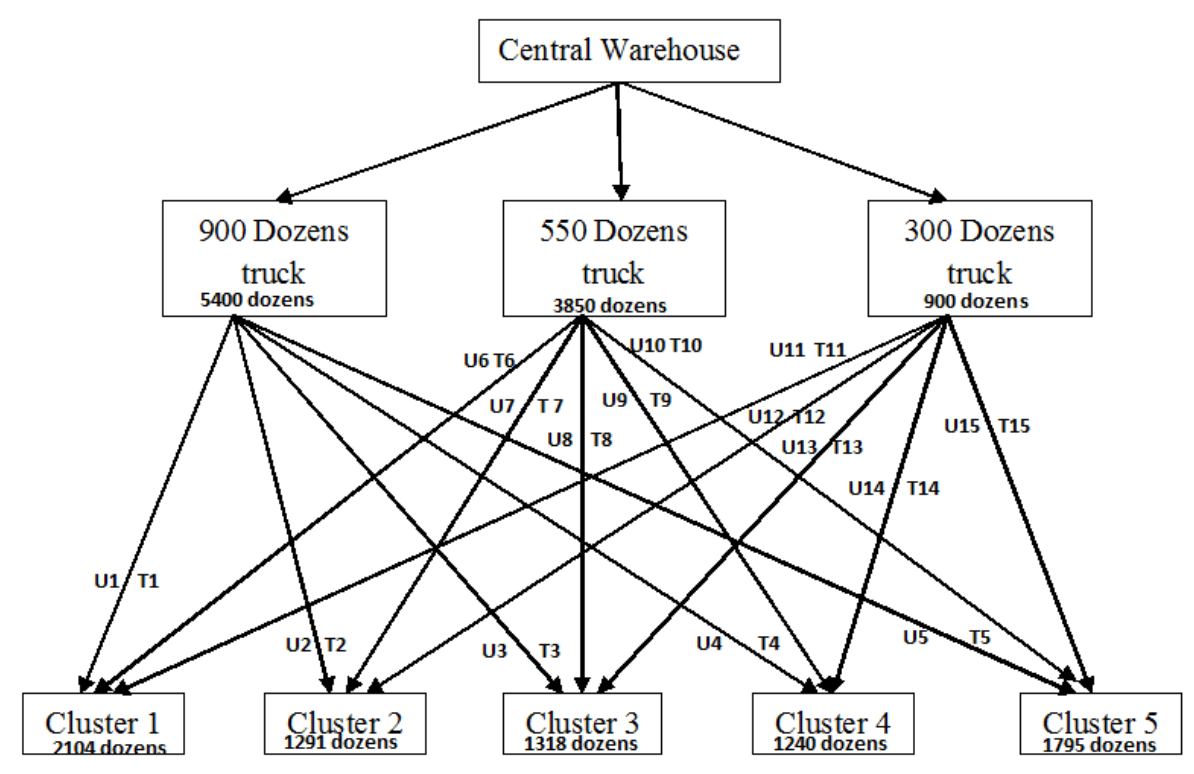

Source: Constructed by the author

To find a truck allocation for the each path, above structure was developed and used linear programming methods to solved the transpotation plan problem.

\section{Discussion and results}

\section{Table 4: Monthly Cost Difference between Existing System and Proposed System}

Existing System

\begin{tabular}{|c|c|c|c|c|c|c|c|c|c|c|}
\hline \multirow{3}{*}{ Description } & \multirow{3}{*}{ Cost } & \multicolumn{6}{|c|}{ Distributor Name } & \multicolumn{3}{|c|}{ Proposed System } \\
\hline & & \multicolumn{2}{|c|}{ Bora } & \multicolumn{2}{|c|}{ Col 6} & \multicolumn{2}{|c|}{ Col 13} & \multirow[t]{2}{*}{ Total Cost } & \multirow[b]{2}{*}{ Qty } & \multirow[b]{2}{*}{ Cost } \\
\hline & & Qty & Cost & Qty & Cost & Qty & Cost & & & \\
\hline Warehouse Rent & & & 100000 & & 420000 & & 265000 & 785000 & & 366852.8 \\
\hline Lorry Lease & 75000 & 6 & 450000 & 5 & 375000 & 5 & 375000 & 1200000 & 13 & 975000 \\
\hline Lorry Insurance & 3668 & 6 & 22008 & 5 & 18340 & 5 & 18340 & 58688 & 13 & 47684 \\
\hline Insurance for Goods & 23000 & 6 & 138000 & 5 & 115000 & 5 & 115000 & 368000 & 13 & 299000 \\
\hline License & 167 & 6 & 1002 & 5 & 835 & 5 & 835 & 2672 & 13 & 2171 \\
\hline Other Expenses & 3750 & 6 & 22500 & 5 & 18750 & 5 & 18750 & 60000 & 13 & 48750 \\
\hline Transport cost & 41.71 & & & & & & & 628986.8 & & 600790.84 \\
\hline Salaries and Wages & & & & & & & & 2959400 & & 2398200 \\
\hline Electricity & 2000 & & 2000 & & 2000 & & 2000 & 6000 & & 6000 \\
\hline Water & 2000 & & 2000 & & 2000 & & 2000 & 6000 & & 6000 \\
\hline Total Cost & & & & & & & & 6074747.8 & & 4750448.64 \\
\hline
\end{tabular}

Source: Constructed by the author according to the data of ROI model

According to the Table 4, it is showing monthly cost difference of two systems. All costs fixed by the Lion Brewery and electricity, water and even milk run total kilometers also fixed. If those costs exceed, distributor have to bare that cost. Fixed kilometers are given Table 4.7 and transport cost is given Table 4.8 existing system is operating 16 trucks (Boralasgamuwa - 6, Colombo $6-5$, Colombo $13-5$ ) but proposed system needs only 13 
trucks. Total cost of existing system is Rs 6074747.8 and proposed system cost is 4750448.64 . Proposed systems brings saving of Rs 1324299.16 per month and it is $21.8 \%$ savings of existing system.

\section{Conclusion}

To analyse research, it has been used secondary data which has collected from SAP and Agent operation data base in Lion Brewery Ceylon PLC. Research has limited in Colombo region. When implementing central warehouse strategies, location should be found through demand. Colombo region has been divided in to 35 clusters and weight allocated to each sub cluster according to demand. After finding locations of each clusters (latitude and longitude), Gravity model has been given location of new facility. It is situated in latitude 6.887700861 and longitude 79.90165817.

According to location, sub clusters divided in to five main clusters and Hamiltonian cycle has given optimal path between sub clusters. Hamiltonian cycle problem has been solved using Lingo software. 900, 550 and 300 dozens capacity Trucks have used to redistribute goods and those are allocated each optimal path given by Hamiltonian cycle. Linear programming has been built and it is solved using MS Solver. Given solution was critical because some trucks unit cost had been increased and need more trucks than existing trucks. Therefore manual adjustment has been introduced by considering transport unit cost. Trucks have allocated according to the units cost while satisfying daily demand. When considering daily transportation cost between existing model and proposed model, 26 kilometers have been saved profit is Rs 1084.46 per day. Existing model is running 16 redistribution trucks and proposed system can be covered, it using 13 trucks. 5 days demand has been taken as a safety stock and Cost of the central warehouse is Rs 366852.8 and it is saving Rs 418147.2. Salaries and Wages are given cost savings Rs 561200 .

When comparing total cost of proposed model and existing model, proposed model has been saved Rs 1324299.16 per month. Centralized distribution strategies give cost benefit rather than Decentralized distribution Strategies. For the future development of this research linear programming model must be develop without manual adjustment.

\section{Appendix A. Supplementary material}

Supplementary data associated with this article can be found, in the online version, at https://jsdtl.sciview.net

\section{Funding}

The authors received no direct funding for this research.

\section{Citation information}

Ganepola, D. D., Jayarathna, N. D., \& Madhushani, G. (2018). An intelligent cost optimized central warehouse and redistribution root plan with truck allocation system in Colombo region for Lion Brewery Ceylon PLC. Journal of Sustainable Development of Transport and Logistics, 3(2), 66-73. doi:10.14254/jsdtl.2018.3-2.4.

\section{References}

Bidaud, J., \& Safir, C. (2008). Pre study for a central warehouse. Central Europe: The school of industrial engineering and management of KTH.

Chalaturnyk, A. (2008). A Fast Algorithm For Finding Hamilton Cycles. Winnipeg: University of Manitoba.

Dai, P. J., \& Zhou, P. C. (2008). Beer Distribution in China. Atlanta: Georgia Institute of Technology.

Drezner, Z., Scott, C., \& Song, J. S. (2009) The Central Warehouse Location Problem Revisited. Irvine: University of California.

Hamiltonian path. (2014, December 22 ). Retrieved 11 12, 2014, from Wikipedia, the free encyclopedia: http://en.wikipedia.org/wiki/Hamiltonian_path

Haythorpe, M. (2000). Markov Chain Based Algorithms for the Hamiltonian Cycle Problem. South Australia: University of South Australia. 
Machackova, J. (2009). Economic Evaluation of a Warehouse Investment in Central Europe: Case Study at Nokian Heavy Tyer Limited. Europe: University of Applied Science.

PLC, L. B. (2013). Annual Report. Biyagama: Lion Brewery Ceylon PLC.

Sahoo, S., \& Pal, D. B. (2012). Truck allocation model using linear programming and queueing theory. Rourkela: National Institute of Technology.

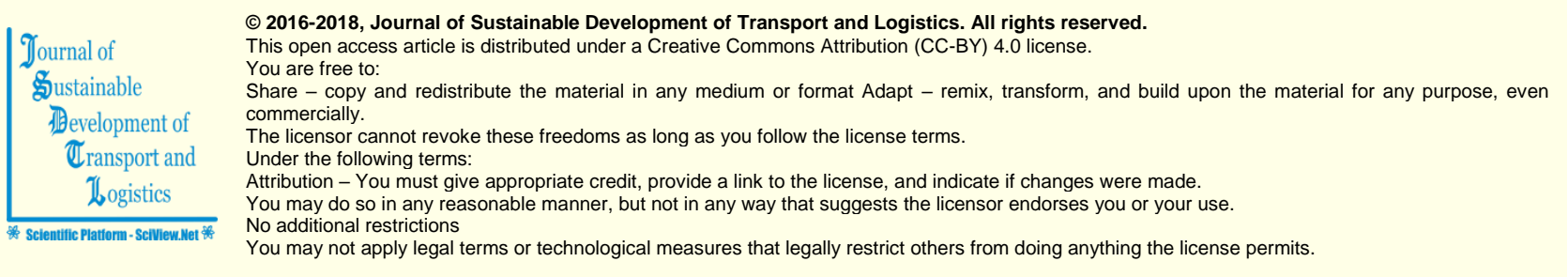

Journal of Sustainable Development of Transport and Logistics (ISSN: 2520-2979) is published by Scientific Publishing House "CSR", Poland, EU and Scientific Publishing House "SciView", Poland, EU

Publishing with JSDTL ensures:

- Immediate, universal access to your article on publication

- High visibility and discoverability via the JSDTL website

- Rapid publication

- Rapid publication

- Discounts and waivers for authors in developing regions

Submit your manuscript to a JSDTL at https://jsdtl.sciview.net/ or submit.jsdt|@sciview.net 